\title{
INHIBITION OF THE CORROSION OF MILD STEEL IN HYDROCHLORIC ACID BY ISATIN AND ISATIN GLYCINE
}

\author{
B.I. Ita \\ Department of Pure and Applied Chemistry, University of Calabar, University of Calabar Post \\ Office, P.O. Box 3700, Calabar, CRS, Nigeria
}

(Received March 8, 2005; revised January 22, 2006)

\begin{abstract}
The inhibition of corrosion of mild steel in hydrochloric acid by isatin glycine (ING) and isatin (IN) at $30-60{ }^{\circ} \mathrm{C}$ and concentrations of $0.0001 \mathrm{M}$ to $0.0005 \mathrm{M}$ was studied via weight loss method. At the highest inhibitor concentration studied ING exhibited inhibition efficiency of 87\% while IN exhibited $84 \%$ at $60{ }^{\circ} \mathrm{C}$. A chemical adsorption mechanism was proposed on the basis of the temperature effect and obtained average activation energy values of $143.9 \mathrm{~kJ} / \mathrm{mol}$ for ING and $118.5 \mathrm{~kJ} / \mathrm{mol}$ for IN. The two inhibitors were confirmed to obey the Langmuir adsorption isotherm equation at the concentrations studied. Also a first-order type of mechanism was proposed from the kinetic treatment of the result. The difference in the inhibitory properties of the inhibitors was explained in terms of the difference in their molecular structures and solubility rather than difference in molecular weights alone.
\end{abstract}

KEY WORDS: Corrosion, Inhibition of corrosion, Mild steel, Isatin glycine, Isatin, Adsorption

\section{INTRODUCTION}

Traditional corrosion inhibitors for metals in hydrochloric acid are mostly toxic and environmentally damaging. Recent interest has been shifted to investigating on the corrosion inhibitory properties of non-toxic inhibitors involving amino acids and derivatives [1-2]. Earlier, in our laboratory non-toxic dyes have been reported as corrosion inhibitors for mild steel [3-5]. The present report assesses yet the inhibitory properties of isatin (IN) and isatin glycine (ING) on mild steel corroded by hydrochloric acid using the weight loss technique. To the best of our knowledge isatin (IN) and isatin glycine (ING) have not yet been reported as corrosion inhibitors for mild steel in $0.1 \mathrm{M} \mathrm{HCl}$ solution in the literature. The aim of this investigation was to evaluate the effect of molecular size, changing functional and structural groups on the protection efficiency imparted by the molecules. The temperature effect on inhibition has also been incorporated into the studies. The data obtained has been interpreted kinetically and thermodynamically.

\section{EXPERIMENTAL}

\section{Material preparation}

The sheet of mild steel was obtained from System Metals Industries Ltd., Calabar, Nigeria. The sheet was $0.07 \mathrm{~cm}$ in thickness and purity of $98.774 \% \mathrm{Fe}$. The chemical composition of the mild steel sheet was $\mathrm{C}=0.12 \%, \mathrm{Mn}=0.90 \%, \mathrm{~S}=0.066 \%, \mathrm{P}=0.050 \%, \mathrm{Si}=0.10 \%$ and remainder Fe. The sheet was mechanically press-cut into $5 \mathrm{x} 4 \mathrm{~cm}$ coupons and holes of about $0.02 \mathrm{~cm}$ in diameter were drilled on the centre of the shorter sides of all the coupons for the insertion of glass hooks for suspension. The total geometric surface area was $40.0 \mathrm{~cm}^{2}$ and the average

*Corresponding author. E-mail: iserom2001@ yahoo.com 
weight of a coupon was about $12.0 \mathrm{~g}$. The coupons were used as supplied without further polishing but each coupon was degreased in absolute ethanol and cleaned by mild scrubbing with bristle brush, rinsed in absolute ethanol again and then dried in acetone. These coupons were then stored in a desiccator in the absence of moisture before their use for the investigation.

The additives used as inhibitors were isatin glycine (ING) (Figure 1) and isatin (IN) (Figure 2) (obtained from BDH, England). These additives were prepared in concentrations of 0.0001 to $0.0005 \mathrm{M}$ in the increment of 0.0001 in $0.1 \mathrm{M} \mathrm{HCl}$ solution. The prepared additive solutions were used for all measurements.

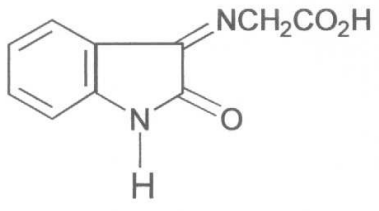

Figure 1. Isatin glycine (ING).

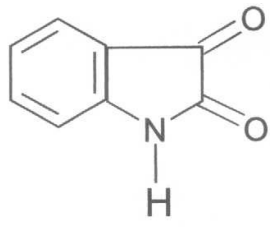

Figure 2. Isatin (IN).

\section{Weight loss determination}

Five $250 \mathrm{~mL}$ beakers which separately contained $0.1,0.2,0.3,0.4$ and $0.5 \mathrm{M} \mathrm{HCl}$ solutions, were placed in three thermostat baths maintained at 40,50 and $60{ }^{\circ} \mathrm{C}$, constituting three sets of experiments. The next set of experiments was made up of another five $250 \mathrm{~mL}$ beakers each containing $0.1,0.2,0.3,0.4$ and $0.5 \mathrm{M} \mathrm{HCl}$ solutions at room temperature $\left(30 \pm 1{ }^{\circ} \mathrm{C}\right)$.

The weighed coupons were each suspended in a beaker with the help of glass hooks and glass rods. These coupons were retrieved at $24 \mathrm{~h}$ intervals progressively for $168 \mathrm{~h}$ ( 7 days). Each retrieved coupon was washed several times in $20 \% \mathrm{NaOH}$ containing $200 \mathrm{~g} / \mathrm{L}$ of zinc dust until clean, dried in acetone and re-weighed [6]. The weight was evaluated in $\mathrm{g}$. A reading reported represented the average of three readings recorded on a Mettler H 35 AR analytical balance to the nearest $0.0001 \mathrm{~g}$. Further measurements using weight loss determination involved the introduction of the inhibitors into four sets each of ten beakers maintained at 30, 40,50 and $60{ }^{\circ} \mathrm{C}$. Each previously weighed mild steel coupon was introduced into five of the ten beakers containing isatin (IN) and the other five beakers containing isatin glycine (ING). The experiments in the presence of the additives were performed differently. As described earlier, each coupon was also retrieved from the corrodent $(\mathrm{HCl})$-inhibitor solutions every $24 \mathrm{~h}$ for the period of $168 \mathrm{~h}$, washed and weighed. The difference in weight of the coupons was taken as the weight loss $(\Delta \mathrm{W})$ defined as

$$
\Delta \mathrm{W}=\mathrm{W}_{\mathrm{o}}-\mathrm{W}_{\mathrm{t}}
$$

where $\mathrm{W}_{\mathrm{o}}$ is the weight of mild steel at time $\mathrm{t}=0$ and $\mathrm{W}_{\mathrm{t}}$ is the weight of mild steel at time, $\mathrm{t}$.

\section{RESULTS AND DISCUSSION}

\section{Effect of inhibitor concentration}

Figure 3 indicates that ING and IN actually inhibit the acid corrosion of mild steel to an appreciable extent. The inhibition efficiencies, I.E. (\%), of the inhibitors are obtained from their weight loss data using the equation (2) [7] below:

$$
\text { I.E. }(\%)=\left[\left(\Delta \mathrm{W}_{\mathrm{o}}-\Delta \mathrm{W}_{\mathrm{i}}\right) / \Delta \mathrm{W}_{\mathrm{o}}\right] \times 100
$$


where $\Delta \mathrm{W}_{\mathrm{o}}$ and $\Delta \mathrm{W}_{\mathrm{i}}$ are the weight losses in the absence and in the presence of the inhibitors, respectively. The data for I.E. (\%) form the basis of Figure 4, which indicates that inhibition efficiency increases with increasing inhibitor concentration and with increasing temperature for both inhibitors. The important findings from Figure 4 indicate that ING inhibits the corrosion of mild steel in $0.1 \mathrm{M} \mathrm{HCl}$ solution more efficiently than IN. The ING exhibited a higher maximum inhibition efficiency of $87 \%$ at $60{ }^{\circ} \mathrm{C}$ than IN which shows $84 \%$ efficiency at same temperature of $60{ }^{\circ} \mathrm{C}$. The general increase in inhibition efficiency observed with increased temperature for ING and IN is suggestive of the existence of very strong adsorption interaction between the mild steel surface and the inhibitors which is chemical in nature [8]. This observation is supported by the fact that ING has a higher average E value of $143.9 \mathrm{~kJ} / \mathrm{mol}$ than IN which has lower average $\mathrm{E}$ value of $118.5 \mathrm{~kJ} / \mathrm{mol}$. Activation energy values above $80 \mathrm{~kJ} / \mathrm{mol}$ signify chemical adsorption process [9].
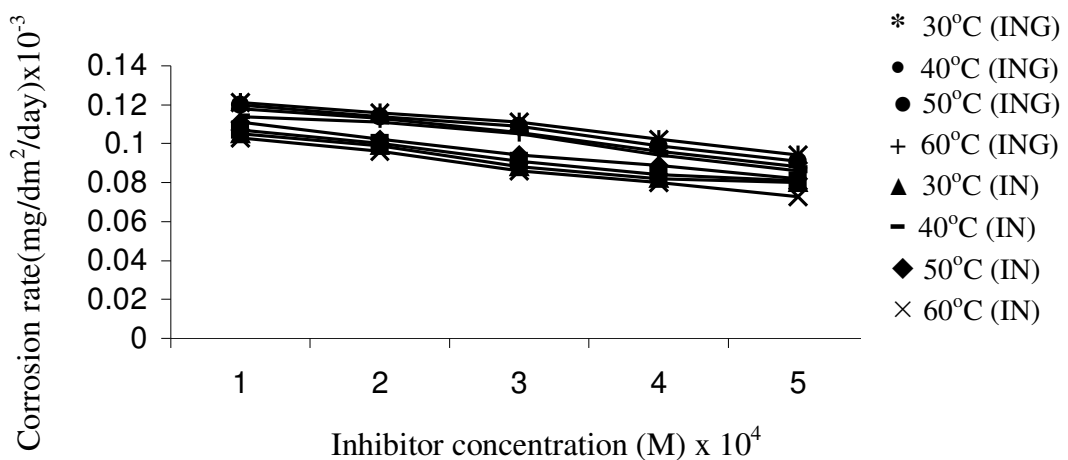

Inhibitor concentration $(\mathrm{M}) \times 10^{4}$

Figure 3. Variation of corrosion rate $\left(\mathrm{mg} / \mathrm{dm}^{2} /\right.$ day) with inhibitor concentration for mild steel in $0.1 \mathrm{M} \mathrm{HCl}$ containing ING and IN at different temperatures.

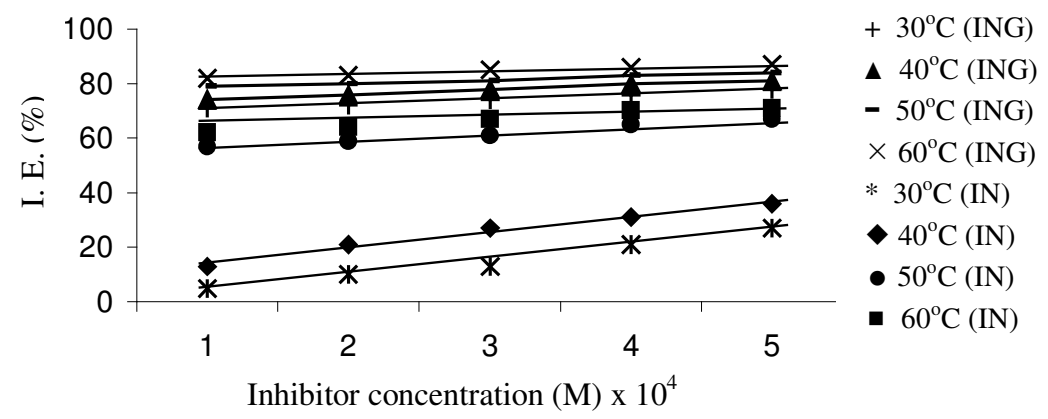

Figure 4. Variation of inhibition efficiency, I.E. (\%) with inhibitor concentration (M) for mild steel in $0.1 \mathrm{M} \mathrm{HCl}$ containing ING and IN at different temperatures.

\section{Kinetic treatment of weight loss result with inhibitor}

The kinetic treatment of the results reveals that ING and IN inhibit mild steel corrosion via a first-order mechanism. The ING exhibits comparatively lower corrosion rates than IN. The ING also exhibits higher half-life, $t^{1} / 2$ (days) than IN, signifying that the mild steel remains more protected in ING-HCl system and for longer period than in the IN-HCl system [8]. The values of 
the activation energies and other kinetic parameters are recorded in Table 1. The average E values also reveal that ING with a higher E value than that of IN is the better inhibitor.

Table 1A. Kinetic and thermodynamic data for the corrosion of mild steel in $0.1 \mathrm{M} \mathrm{HCl}$ solution containing ING from weight loss measurements.

\begin{tabular}{|l|l|l|l|l|l|l|}
\hline $\begin{array}{l}\text { Inhibitor } \\
\text { concentration } \\
(\mathrm{M}) \times 10^{4}\end{array}$ & $\begin{array}{l}\mathrm{k}_{30} \\
\left(\mathrm{day}^{-1}\right)\end{array}$ & $\begin{array}{l}\mathrm{k}_{40} \\
\left(\mathrm{day}^{-1}\right)\end{array}$ & $\begin{array}{l}\mathrm{E} \\
(\mathrm{kJ} / \mathrm{mol})\end{array}$ & $\begin{array}{l}\Delta \mathrm{H}^{\mathrm{0}} \\
\left(\mathrm{Jmol}^{-1}\right)\end{array}$ & $\begin{array}{l}\mathrm{t}^{1} / 2(30) \\
(\mathrm{day})\end{array}$ & $\begin{array}{l}\mathrm{t}^{1} / 2(40) \\
(\text { day })\end{array}$ \\
\hline 1 & 0.000169 & 0.000035 & 90.9 & -1.42 & 4101 & 19800 \\
\hline 2 & 0.000223 & 0.000030 & 124.9 & -1.28 & 3108 & 23100 \\
\hline 3 & 0.000230 & 0.000025 & 141.9 & -1.58 & 3013 & 27720 \\
\hline 4 & 0.000207 & 0.000016 & 168.9 & -1.67 & 3348 & 43313 \\
\hline 5 & 0.000088 & 0.000005 & 192.9 & -1.74 & 7875 & 138600 \\
\hline
\end{tabular}

Average $\mathrm{E}=143.9 \mathrm{~kJ} / \mathrm{mol}$.

Table 1B. Kinetic and thermodynamic data for the corrosion of mild steel in $0.1 \mathrm{M} \mathrm{HCl}$ solution containing IN from weight loss measurements.

\begin{tabular}{|l|l|l|l|l|l|l|}
\hline $\begin{array}{l}\text { Inhibitor } \\
\text { concentration } \\
(\mathrm{M}) \times 10^{4}\end{array}$ & $\begin{array}{l}\mathrm{k}_{30} \\
\left(\mathrm{day}^{-1}\right)\end{array}$ & $\begin{array}{l}\mathrm{k}_{40} \\
\left(\mathrm{day}^{-1}\right)\end{array}$ & $\begin{array}{l}\mathrm{E} \\
(\mathrm{kJ} / \mathrm{mol})\end{array}$ & $\begin{array}{l}\Delta \mathrm{H}^{\mathrm{0}} \\
\left(\mathrm{Jmol}^{-1}\right)\end{array}$ & $\begin{array}{l}\mathrm{t}^{1} / 2(30) \\
(\mathrm{day})\end{array}$ & $\begin{array}{l}\mathrm{t}^{1} / 2(40) \\
(\text { day })\end{array}$ \\
\hline 1 & 0.000691 & 0.000145 & 89.9 & -1.28 & 1003 & 4779 \\
\hline 2 & 0.000729 & 0.000120 & 109.1 & -1.15 & 951 & 5775 \\
\hline 3 & 0.000806 & 0.000116 & 119.9 & -1.25 & 860 & 5974 \\
\hline 4 & 0.000883 & 0.000106 & 133.9 & -1.46 & 785 & 6538 \\
\hline 5 & 0.000902 & 0.000100 & 139.9 & -1.53 & 768 & 6930 \\
\hline
\end{tabular}

Average $\mathrm{E}=118.5 \mathrm{~kJ} / \mathrm{mol}$.

\section{Comparison of the corrosion inhibition behaviours of ING and IN}

From the weight loss measurement, the inhibitory actions of ING and IN reveal that ING exhibits a better corrosion inhibition tendency than IN. The inhibitor's action is suggestive of an adsorption mechanism onto the mild steel surface. For the given inhibitor, an increase in its concentration generally increases inhibition efficiency. On the basis of increasing inhibition efficiency with increasing temperature, ING and IN are chemically adsorbed on the mild steel coupons used at the temperatures of the investigation. Figure 5 is the curve-fitting following the transition state theory for ING and IN, respectively. The $\Delta \mathrm{H}^{\mathrm{o}}$ obtained from the slope of Figure 5 shows a higher magnitude at $0.0005 \mathrm{M}$ inhibitor concentration than at $0.0001 \mathrm{M}$ for ING and IN. Also the values of $\Delta \mathrm{H}^{\mathrm{o}}$ for ING are more negative than those of IN, which further add impetus to the claim that ING inhibits mild steel corrosion better than IN. The effect of temperature on the corrosion rate in the absence and presence of the inhibitors was used to elucidate the nature of adsorption of the inhibitors onto the mild steel surface. The two inhibitors (ING and IN) have data which fit into the Langmuir isotherm formulated as [10]:

$$
\log (\theta / 1-\theta)=K^{1}+1 / x \log C
$$

where $\theta$ is the degree of coverage defined as I.E. $(\%) / 100, \mathrm{x}$ is the number of inhibitor molecules occupying one active site (or the number of water molecules replaced by one molecule of ING or IN), $\mathrm{K}^{1}$ is a constant which is related to the equilibrium constant of the adsorption reaction as $\mathrm{K}=\mathrm{K}^{1(\mathrm{x})}$. Figure 6 is curve-fitting of data to equation (3). These data give straight lines. The values of $\mathrm{K}^{1}, \mathrm{x}$ and $\mathrm{K}$ are shown in Table 2 for ING and IN. The value of $\mathrm{K}$, 
the equilibrium constant, increases with temperature suggesting that ING and IN are both chemically adsorbed on the mild steel surface and it is the desorption process that is enhanced with decreasing temperature. Another important parameter normally used to discover the nature of adsorption is the activation energy, E values. Table 1 indicates that ING has a higher average E value of $143.9 \mathrm{~kJ} / \mathrm{mol}$ than IN which has average E value of $118.5 \mathrm{~kJ} / \mathrm{mol}$. The activation energy value of a particular inhibitor $\mathrm{E}$ was obtained from the equation [8]:

$$
\mathrm{E}_{\mathrm{i}}=\mathrm{E}_{\mathrm{a}}-\mathrm{E}_{\mathrm{b}}
$$

where $E_{a}$ is the $E$ value of the metal-corrodent-inhibitor system and $E_{b}$ is the $E$ value of metalcorrodent system $(33.1 \mathrm{~kJ} / \mathrm{mol})$. Therefore ING and IN are both chemically adsorbed on the mild steel surface as these exhibit higher average activation energy above $80 \mathrm{~kJ} / \mathrm{mol}$ [9].

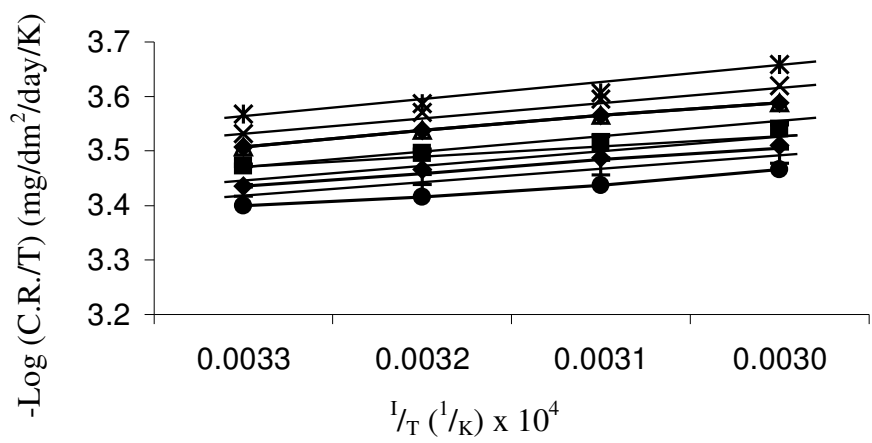

* $1 \times 10^{-4}(\mathrm{INC}$

$\times 2 \times 10^{-4}(\mathrm{INC}$

$\Delta 3 \times 10^{-4}(\mathrm{INC}$

- $4 \times 10^{-4}$ (INC

- $5 \times 10^{-4}$ (INC

v $1 \times 10^{-4}$ (IN)

$2 \times 10^{-4}$ (IN)

$-3 \times 10^{-4}$ (IN)

$+4 \times 10^{-4}$ (IN)

- $5 \times 10^{-4}$ (IN)

Figure 5. Variation of $\log (\mathrm{C} . \mathrm{R} . / \mathrm{T})\left(\mathrm{mg} / \mathrm{dm}^{2} /\right.$ day/K) with $1 / \mathrm{T}(1 / \mathrm{K})$ for mild steel in $0.1 \mathrm{M} \mathrm{HCl}$ containing ING and IN.

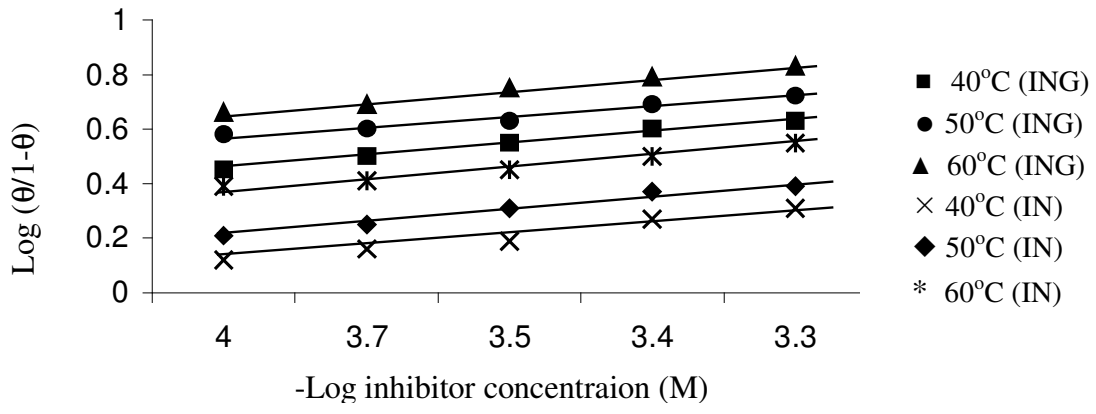

Figure 6. Variation of $\log (\theta / 1-\theta)$ with $\log$ inhibitor concentration (M) for mild steel in $0.1 \mathrm{M}$ $\mathrm{HCl}$ containing ING and IN at different temperatures.

Table 2. Other thermodynamic data for the corrosion of mild steel in $0.1 \mathrm{M} \mathrm{HCl}$ solution containing ING and IN from weight loss measurements.

\begin{tabular}{|l|l|l|l|l|l|l|}
\hline & \multicolumn{4}{|l|}{ ING } & \multicolumn{2}{l|}{ IN } \\
\hline Temperature $\left({ }^{\circ} \mathrm{C}\right)$ & $\mathrm{K}^{1}$ & $\mathrm{x}$ & $\mathrm{K}$ & $\mathrm{K}^{1}$ & $\mathrm{x}$ & $\mathrm{K}$ \\
\hline 40 & 0.52 & 3.8 & 0.0833 & 0.43 & 3.8 & 0.0405 \\
\hline 50 & 0.75 & 3.9 & 0.3257 & 0.62 & 4.4 & 0.1221 \\
\hline 60 & 0.95 & 4.1 & 0.8103 & 0.86 & 5.0 & 0.4704 \\
\hline
\end{tabular}


The difference in the inhibitory properties of the inhibitors is closely related to the difference in their molecular structures and solubility rather than difference in molecular weights alone. The ING also has a higher molecular weight ( 204) than IN ( 147). Therefore it is assumed that ING could form a more functional blanket-like layer on the mild steel surface than IN. Also, ING was found to be more soluble in $0.1 \mathrm{M} \mathrm{HCl}$ solution than IN which was only slightly soluble in the solution. Solubility plays a very crucial role when considering chemical adsorption mechanism [11]. The above could go a long way to unravel the reason why ING is a more effective chemisorbed inhibitor than IN. Moreover structural consideration must be given here to explain why ING is more effective than IN. Figures 1 and 2 show that the two inhibitors contain pi-bonds in their molecules which normally coordinate with the available d-orbital of the metal. The two structures are however very similar except that for ING the number 3position carries $=\mathrm{NCH}_{2} \mathrm{CO}_{2} \mathrm{H}$ group while for IN the number 3-position carries only $=\mathrm{O}$. Other parts of the molecule are similar in the two cases (i.e. in ING and IN). Due to the high electronegativity of nitrogen, electrons tend to pull towards the $\mathrm{N}$ atom in ING so that the $\mathrm{N}$ atom becomes more electron rich thereby being able to form strong coordinate bond with the metal ion. A greater contribution to stronger chemisorbed bond by ING may arise from the possibility of forming a covalent bond between the $-\mathrm{COOH}$ and $-\mathrm{OH}$ groups on the mild steel surface leading to $\mathrm{C}-\mathrm{O}-\mathrm{Fe}$ bonds. But IN may not be able to form such a strong bond. This probably also explains why ING is a better inhibitor than IN for mild steel in $0.1 \mathrm{M} \mathrm{HCl}$ solution.

\section{CONCLUSION}

The compounds (ING and IN) used as inhibitors have highly significant effects on the corrosion of mild steel in hydrochloric acid. Inhibition by these compounds increases with increased inhibitor concentration and increased temperature. The ING and IN inhibited the corrosion reaction, probably getting chemically adsorbed onto the mild steel surface.

\section{REFERENCES}

1. Abdel, M.A.; Hassan, H.B.; Khalil, M.W. Materialwiss. Werkstofftech. 1997, 28, 98.

2. Al-Mayouf, A.M. Corros. Prev. Control. 1996, 43, 68.

3. Ita, B.I.; Edem, C.A. Global J. Pure Appl. Sci. 2000, 6, 330.

4. Ebenso, E.E.; Ekpe, U. J. W. Afr. J. Biol. Appl. Chem. 1996, 41, 21.

5 Ebenso, E.E. Nig. Corros. J. 1998, 1, 29.

6. Ita, B.I.; Offiong, O.E., Mater. Chem. Phys. 2001, 70, 330.

7. Ita, B.I. J. Nig. Env. Soc. 2003, 1, 113.

8. Ebenso, E.E.; Okafor, P.C.; Offiong, O.E.; Ita, B.I.; Ibok, U.J.; Ekpe, U.J. Bull. Electrochem. 2001, 17, 259.

9. Barrow, G.M. Physical Chemistry, 4th ed., McGraw-Hill: New York; 1983, 739.

10. Gomma, G.K. J. Indian Chem. Soc. 1993, 70, 130.

11. Hackerman, N. Trans. New York Acad. Sci. 1954, 17, 7. 